\title{
Reoperative Urethroplasty after Failed Hypospadias Repair
}

\author{
MOHAMMED A. ZEDAN, M.Sc.; TAREK A. GAMEEL, M.D.; MOHAMMED A. GHALWASH, M.D. and \\ OSAMA M. EL-GAMAL, M.D.
}

The Department of Urology, Faculty of Medicine, Tanta University, Egypt

\begin{abstract}
Background: Reported reoperation rates after primary hypospadias repair can exceed 50\%. Failed hypospadias occurs when the primary surgery does not achieve the cosmetic and functional goals of a straight penis with glanular meatus that enables normal urinary and sexual function. Treatment of patients with failed hypospadias repair can be a challenging task in the majority of cases and the selection of the most appropriate technique for this repair is the corner stone for success in these cases.
\end{abstract}

Aim of Study: Is to evaluate the results and success rate of some common techniques for redo urethroplasty in cases with failed hypospadias repair.

Patients and Methods: The study included forty two patients with recurrent hypospadias and their ages ranged from 2-15 years. The final position of the external urethral meatus after release of chordee, was subcoronal (13 cases), distal penile (13 cases), mid-penile (13 cases) and penoscrotal ( 3 cases). TIP technique was applied in 12 cases, Mathieu technique in 10 cases, transverse dorsal preputial onlay flap in 10 cases and two-stage repair with buccal mucosa graft in 10 cases. The operative technique was selected according to the status of the urethral plate and the nearby penile skin.

Results: Our overall results showed that 24 patients $(57.14 \%)$ had successful repair while failed repair was reported in 8 patients $(19.04 \%)$. Minor complications were also reported in 10 cases $(23.80 \%)$ which included urethrocutaneous fistula, meatal stenosis and urethral diverticulum. The success rates of TIP, Mathieu, transverse dorsal preputial onlay flap and the two-stage repair were $58.33 \%, 50 \%, 50 \%$ and $70 \%$ respectively.

Conclusion: TIP urethroplasty is an effective technique for redo hypospadias repair if the patient has a non-scarred and wide urethral plate. Similar results can also be achieved by Mathieu's repair or transverse onlay flap in patients with narrow and non-scarred urethral plate. However, patient with scarred unhealthy urethral plate should have a two stage repair with buccal mucosa graft.

Key Words: Hypospadias-reoperation - Hypospadias complications - Risks for hypospadias - Complications.

Correspondence to: Dr. Mohammed A. Zedan, E-Mail: dr zedan89@yahoo.com

\section{Introduction}

HYPOSPADIAS is one of the most common congenital anomalies with a prevalence of 3 to 5 per 1,000 births [1]. The reported reoperation rates after primary repair of these cases can exceed 50\% [2]. Failed hypospadias occurs when the primary surgery does not achieve the cosmetic and functional goals of a straight penis with a glanular meatus that enables normal urinary and sexual function. Failed hypospadias includes all complicated repairs that don't fulfill patient expectations and cause dissatisfaction [3].

Risk factors affecting complications and success rate in redo hypospadias repair include factors related to the hypospadias (severity of the condition and characteristics of the urethral plate), the patient (age at surgery, endocrine environment and wound healing impairment), the surgeon (technique selection and surgeon expertise) and the procedure (technical details, suture materials, urethral stenting and postoperative management). The most important factors for preventing complications are surgeon expertise (number of cases treated per year), interposition of a barrier layer between the urethroplasty and the penile skin and postoperative urinary drainage [4].

In general, the technique used for repair is determined intraoperatively after careful reassessment of the meatus location, penile curvature, final size and the ventral aspect of the penile skin [2] However, different techniques can be used in redo hypospadias repair as TIP repair, Mathieu repair, two stage repair, onlay flap ....etc [5].

In this project, we have studied the results of some techniques that were selected for redo surgery in patients with failed hypospadias repair. 


\section{Patients and Methods}

In this prospective study we included 42 boys with failed hypospadias repair. The study period started from May 2017 to December 2018 and was conducted at the Pediatric Urology Unit of the Urology Department at Tanta University Hospitals.

Our study was approved by the local Ethics and Research Committee at Tanta Faculty of Medicine under number 31441/03/17; an informed consent was obtained from all participants before enrollment in the study.

At least 6 months should pass after the last hypospadias repair before recruitment of the patients and patients with isolated fistula closure were excluded.

All operations were performed by pediatric urologists with good experience in hypospadias surgery.

Intravenous antibiotic prophylaxis was given before the induction of general anesthesia ( $3 \mathrm{rd}$ generation cephalosporin, $50 \mathrm{mg} / \mathrm{kg}$ ) then caudal block was done to reduce the post-operative pain.

\section{Surgical techniques:}

The following techniques were applied according to the surgical needs of each individual case:

1- Tubularized Incised Plate (TIP) urethroplasty:

It was applied if the urethral plate showed no significant scarring and it was wide enough $>8 \mathrm{~mm}$ with good width of the glans (width $>14 \mathrm{~mm}$ ), and no significant chordee.

2- Mathieu urethroplasty (perimeatal based flap): If the urethral plate shows no significant scarring but it was narrow $<8 \mathrm{~mm}$ and the ventral skin distal to the external urethral meatus looks good.

3- Transverse dorsal preputial onlay flap: It was indicated in cases of healthy narrow urethral plate with intact prepuce.

4- Two-stage repair with buccal mucosa graft:

- First stage: If the urethral plate showed significant scarring and the ventral skin looked unhealthy or in cases of significant chordee $>30^{\circ}$.

- Second stage: It was done after 6 months.

\section{Post-operative care:}

- All patients were discharged on the 2 nd postoperative day and received oral broad spectrum antibiotic for 10 days. They also received antimuscarinic and analgesics to decrease postoperative bladder spasm and pain.
- The dressing was removed after three days and the wound was managed by antibiotic ointment three times daily.

- The urethral catheter was managed by the double diaper technique.

\section{Post-operative follow-up:}

Follow-up visits were scheduled at 2 weeks, 1 month and 3 months post-operatively after catheter removal and patients were assessed for success or presence of early or late complications. In addition, parents' satisfaction was assessed at the ${ }^{3 \mathrm{rd}}$ month post-operatively.

\section{Statistical analysis:}

Statistical analysis was done using IBM SPSS software Version 20.0. (Armonk, NY: IBM Corp). Categorical variables were compared with the chisquared test and numerical variables were compared with ANOVA test. $p<0.05$ was considered statistically significant.

\section{Results}

\section{Pre-operative data:}

The age of our patients ranged from 2-15 years (mean \pm SD $6.94 \pm 3.49$ years). 21 patients had positive family history of hypospadias and 22 patients were uncircumcised when presented to our clinic. 5 patients were associated with congenital inguinal hernia that was repaired in a previous setting. Regarding the associated chordee, 30 patients had no chordee, 7 patients had chordee $<30^{\circ}$ and 5 patients showed chordee $>30^{\circ}$. The final position of the external urethral meatus after release of chordee, was subcoronal, distal penile, mid-penile and penoscrotal in 13,13, 13 and 3 cases respectively. The surgical techniques used for redo repair was TIP, Mathieu, transverse dorsal preputial onlay flap and two-stage repair with buccal mucosa graft in 12,10,10 and 10 cases respectively (Table 1 ).

\section{Post-operative data:}

Regarding the early post-operative complications that occurred during the first two weeks postoperatively, they included penile edema which occurred in 5 patients $(11.90 \%)$. Small sized hematoma occurred in 5 patients $(11.90 \%)$ that resolved spontaneously within the first week postoperatively. Mild wound infection was reported in 6 patients $(14.28 \%)$. Catheter slippage occurred in 2 patients (4.76\%) after 5 days post-operatively in the TIP operation and no attempt for insertion of a new catheter was done as the patients were able to void spontaneously and they had a smooth post- 
operative course. Catheter blockage occurred in 3 patients $(7.14 \%)$ that responded to flushing with normal saline. Complete wound disruption occurred in 6 patients $(14.28 \%)$. Glanular dehiscence was encountered in 2 patients, one case after Mathieu repair and the other after the second stage urethroplasty (Table 3).

Table (1): Distribution of the patients according to patient characteristics.

\begin{tabular}{|c|c|c|}
\hline & $\begin{array}{l}\text { Number of } \\
\text { patients }\end{array}$ & Percentage \\
\hline \multicolumn{3}{|l|}{ Age of the patients: } \\
\hline $2-3 y$ & 10 & $23.80 \%$ \\
\hline $4-6 y$ & 10 & $23.80 \%$ \\
\hline $7-11 y$ & 19 & $45.23 \%$ \\
\hline $12-16 y$ & 3 & $7.14 \%$ \\
\hline Range & $2-15$ & \\
\hline Mean \pm SD & $6.94 \pm 3.49$ & \\
\hline \multicolumn{3}{|l|}{ Family history: } \\
\hline Positive & 21 & $50 \%$ \\
\hline Negative & 21 & $50 \%$ \\
\hline \multicolumn{3}{|l|}{ Associated congenital anomalies: } \\
\hline Congenital inguinal hernia & 5 & $11.90 \%$ \\
\hline Absent & 37 & $88.09 \%$ \\
\hline \multicolumn{3}{|l|}{ Circumcision: } \\
\hline Circumcised & 20 & $47.61 \%$ \\
\hline Uncircumcised & 22 & $52.38 \%$ \\
\hline \multicolumn{3}{|l|}{ Degree of chordee: } \\
\hline$<30$ degree & 7 & $16.66 \%$ \\
\hline$>30$ degree & 5 & $11.90 \%$ \\
\hline No chordee & 30 & $71.42 \%$ \\
\hline \multicolumn{3}{|l|}{ External urethral meatus position: } \\
\hline Subcoronal & 13 & $30.95 \%$ \\
\hline Distal penile & 13 & $30.95 \%$ \\
\hline Mid penile & 13 & $30.95 \%$ \\
\hline Penoscrotal & 3 & $7.14 \%$ \\
\hline \multicolumn{3}{|l|}{$\begin{array}{l}\text { Surgical technique used for redo } \\
\text { surgery: }\end{array}$} \\
\hline TIP & 12 & $28.57 \%$ \\
\hline Mathieu & 10 & $23.80 \%$ \\
\hline Transverse preputial onlay flap & 10 & $23.80 \%$ \\
\hline Two-stage repair & 10 & $23.80 \%$ \\
\hline
\end{tabular}

Table (2): Operative time and urethral catheter duration according to the surgical technique.

\begin{tabular}{lll}
$\begin{array}{l}\text { Surgical } \\
\text { technique used } \\
\text { for redo surgery }\end{array}$ & $\begin{array}{c}\text { Operative time } \\
\text { (minutes) } \\
\text { (mean value } \\
\pm \text { SD) }\end{array}$ & $\begin{array}{c}\text { Urethral catheter } \\
\text { duration (days) } \\
\text { (mean value } \\
\pm \text { SD) }\end{array}$ \\
\hline - TIP & $98.12 \pm 7.03$ & $6.87 \pm 0.98$ \\
- Mathieu & $95.83 \pm 5.84$ & $10.33 \pm 1.36$ \\
- Transverse & $114.16 \pm 8.41$ & $10 \pm 0.63$ \\
preputial onlay & & \\
flap & & 1 st stage: $3.66 \pm 1.17$ \\
Two-stage & 1 st stage: $95 \pm 4.47$ & 2nd stage: $10.6 \pm 0.65$ \\
repair & 2 nd stage: $95 \pm 4.47$ & $3-12$ \\
Range & $90-190$ & $10 \pm 1.12$ \\
\hline
\end{tabular}

Table (3): Distribution of patients according to early and late post-operative complications and overall success rate.

\begin{tabular}{lc}
\hline Percentage & $\begin{array}{c}\text { Number of } \\
\text { patients }\end{array}$ \\
\hline
\end{tabular}

Early post-operative

complications:

- No complications

- Mild wound infection

- Hematoma

- Penile oedema

- Complete wound disruption

- Glanular dehiscence

- Catheter blockage

- Catheter slippage

\begin{tabular}{ll}
13 & $30.95 \%$ \\
6 & $14.28 \%$ \\
5 & $11.90 \%$ \\
5 & $11.90 \%$ \\
6 & $14.28 \%$ \\
2 & $4.76 \%$ \\
3 & $7.14 \%$ \\
2 & $4.76 \%$ \\
& \\
8 & $19.04 \%$ \\
& \\
& \\
6 & $14.28 \%$ \\
5 & $11.90 \%$ \\
2 & $4.76 \%$ \\
& \\
24 & $57.14 \%$ \\
8 & $19.04 \%$ \\
10 & $23.80 \%$ \\
\hline
\end{tabular}

Late post-operative complications:

- Recurrent hypospadias (after

complete wound disruption and glanular dehiscence)

- Urethrocutaneous fistula

- Meatal stenosis

- Urethral diverticulum

$1.90 \%$

Success rate:

- Successful repair

- Failed repair

- Minor complications

$19.04 \%$
$23.80 \%$

Regarding the late post-operative complications that were reported during the period of three months post-operatively, they included urethrocutaneous fistula, meatal stenosis and anterior urethral diverticulum. Urethrocutaneous fistula that was reported in 6 patients $(14.28 \%$ ) ( 2 cases were coronal, 2 cases subcoronal \& 2 cases distal penile). All of these were small fistulae (less than $0.5 \mathrm{~cm}$ ) and repaired by simple fistulectomy. Meatal stenosis occurred in 5 patients $(11.90 \%)$ and three cases were associated with urethrocutanous fistula. Regular dilatation of the external urethral meatus was tried but the five cases were managed by meatotomy and the cases with fistula were managed by simple repair at the same session. Anterior urethral diverticulum occurred in 2 patients $(4.76 \%)$ after transverse dorsal preputial onlay flap that was diagnosed by ascending urethrogram and the two patients underwent diverticulectomy after 6 months as shown in (Table 3).

Our overall results showed that 24 of the 42 patients $(57.14 \%)$ included in this study had successful repair while 8 patients $(19.04 \%)$ had failed repair with recurrent hypospadias due to complete wound disruption or glanular dehiscence and were in need for another redo surgery. On the other hand, minor complications were reported in 10 cases $(23.80 \%)$ as shown in (Table 3$)$.

We have also studied the different factors that could affect the success rate of this surgery, these 
factors included the child age, number of previous repairs, width of the urethral plate, glans width, degree of chordee, final position of external urethral meatus after orthoplasty and type of surgical redo technique as shown in (Table 4). However, our statistical analysis showed that the number of previous operations and the final localization of the urethral meatus after penile orthoplasty were the only significant factors that could affect our success rate (Table 4).

Table (4): Success rate in relation to different pre-operative factors.

\begin{tabular}{|c|c|c|c|}
\hline & $\begin{array}{c}\text { Number } \\
\text { of } \\
\text { patients }\end{array}$ & $\begin{array}{l}\text { Number of } \\
\text { patients with } \\
\text { successful } \\
\text { repairs }\end{array}$ & $\begin{array}{c}\text { Success } \\
\text { rate } \\
\%\end{array}$ \\
\hline $\begin{array}{l}\text { Age group: } \\
\cdot 2-3 \mathrm{y} \\
\cdot 4-6 \mathrm{y} \\
\cdot 7-11 \mathrm{y} \\
\cdot 12-16 \mathrm{y} \\
\cdot \chi^{2} \\
\cdot p \text {-value }\end{array}$ & $\begin{array}{l}10 \\
10 \\
19 \\
3\end{array}$ & $\begin{array}{l}7 \\
4 \\
12 \\
1 \\
0.392 \\
0.941\end{array}$ & $\begin{array}{l}70 \% \\
40 \% \\
57.89 \% \\
33.33 \%\end{array}$ \\
\hline $\begin{array}{l}\text { Number of the previous } \\
\text { operations: } \\
\text { - One } \\
\text { - Two } \\
\text { - Three } \\
\text { : } \chi^{2} \\
p \text {-value }\end{array}$ & $\begin{array}{l}22 \\
13 \\
7\end{array}$ & $\begin{array}{l}15 \\
5 \\
4 \\
3.542 \\
0.024 *\end{array}$ & $\begin{array}{l}68.18 \% \\
38.46 \% \\
57.14 \%\end{array}$ \\
\hline $\begin{array}{l}\text { Urethral plate: } \\
\text { - Wide }<8 \mathrm{~mm} \\
\text { - Narrow <8mm } \\
\text { - }{ }^{2} \\
\text { - } \text {-value }\end{array}$ & $\begin{array}{l}12 \\
20\end{array}$ & $\begin{array}{l}7 \\
10 \\
0.302 \\
0.581\end{array}$ & $\begin{array}{l}58.33 \% \\
50 \%\end{array}$ \\
\hline $\begin{array}{l}\text { Width of the glans: } \\
\cdot>14 \mathrm{~mm} \\
\cdot<14 \mathrm{~mm} \\
\bullet \chi^{2} \\
\cdot p \text {-value }\end{array}$ & $\begin{array}{l}22 \\
20\end{array}$ & $\begin{array}{l}16 \\
8 \\
2.341 \\
0.126\end{array}$ & $\begin{array}{l}72.72 \% \\
40 \%\end{array}$ \\
\hline $\begin{array}{l}\text { Degree of chordee: } \\
\cdot<30 \text { degree } \\
\cdot>30 \text { degree } \\
\cdot \text { No chordee } \\
\cdot \chi^{2} \\
\cdot p \text {-value }\end{array}$ & $\begin{array}{l}7 \\
5 \\
30\end{array}$ & $\begin{array}{l}5 \\
2 \\
17 \\
1.223 \\
0.543\end{array}$ & $\begin{array}{l}71.42 \% \\
40 \% \\
56.66 \%\end{array}$ \\
\hline $\begin{array}{l}\text { Position of the external } \\
\text { urethral meatus: } \\
\text { - Subcoronal } \\
\text { - Distal penile } \\
\text { - Mid penile } \\
\text { - Penoscrotal } \\
\text { - } 2 \text { } \\
\cdot p \text {-value }\end{array}$ & $\begin{array}{l}13 \\
13 \\
13 \\
3\end{array}$ & $\begin{array}{l}11 \\
8 \\
3 \\
2 \\
14.236 \\
0.010^{*}\end{array}$ & $\begin{array}{l}84.61 \% \\
61.53 \% \\
23.07 \% \\
66.66 \%\end{array}$ \\
\hline $\begin{array}{l}\text { Surgical technique: } \\
\text { - TIP } \\
\text { - Mathieu } \\
\text { - Transverse preputial onlay } \\
\text { flap } \\
\text { - Two-stage repair } \\
\text { : }_{p}^{2} \text {-value }\end{array}$ & $\begin{array}{l}12 \\
10 \\
10\end{array}$ & $\begin{array}{l}7 \\
5 \\
5 \\
7 \\
1.424 \\
0.701\end{array}$ & $\begin{array}{l}58.33 \% \\
50 \% \\
50 \% \\
70 \%\end{array}$ \\
\hline
\end{tabular}

*: Statistically significant at $p$-value $\leq 0.05$.

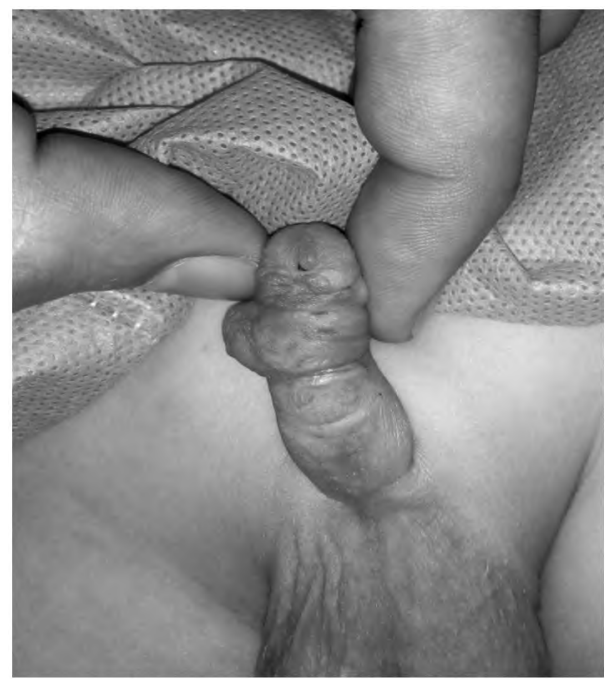

Fig. (1): A case of anterior urethral stricture post mid penile hypospadias repair for redo two stage repair.

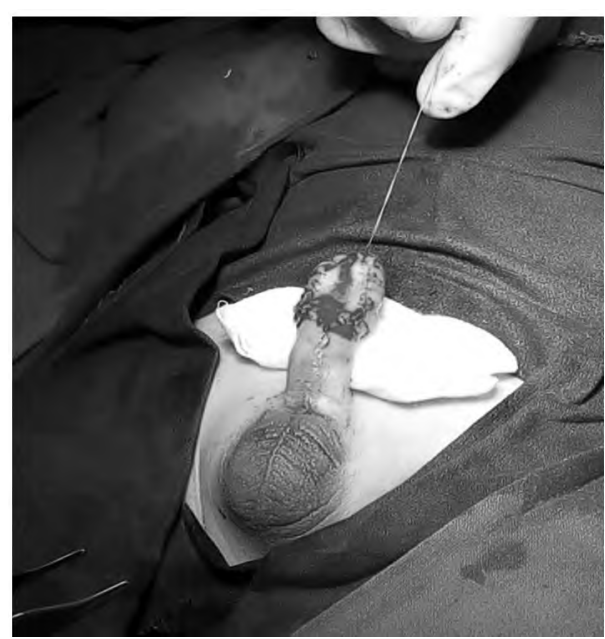

Fig. (2): After fixing the buccal mucosa graft on the urethral plate (first stage repair).

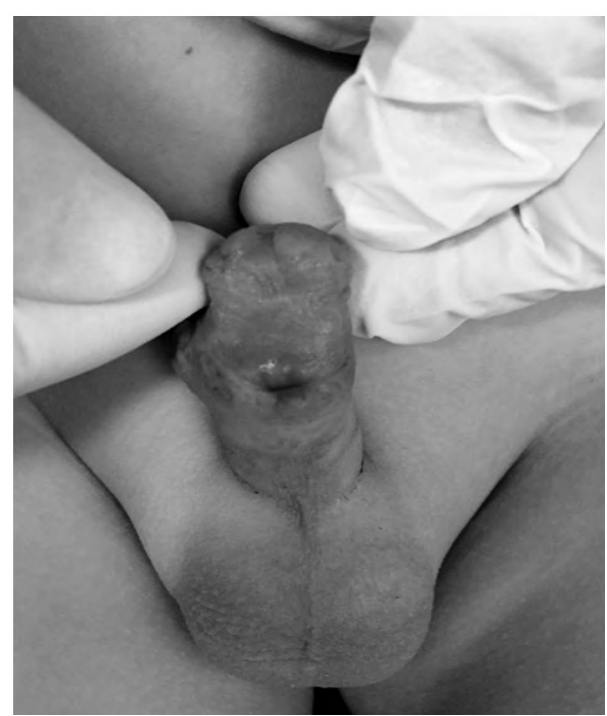

Fig. (3): Final appearance of the penis after the first stage repair (after 2 months). 


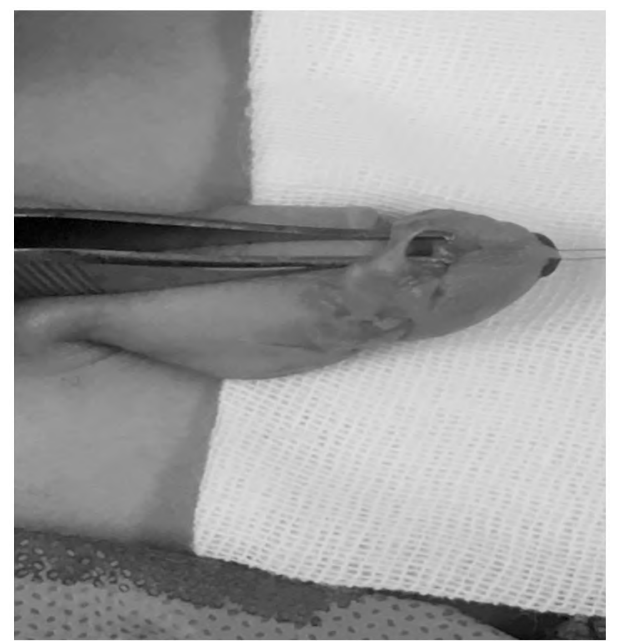

Fig. (4): A case of recurrent coronal hypospadias for redo TIP repair.

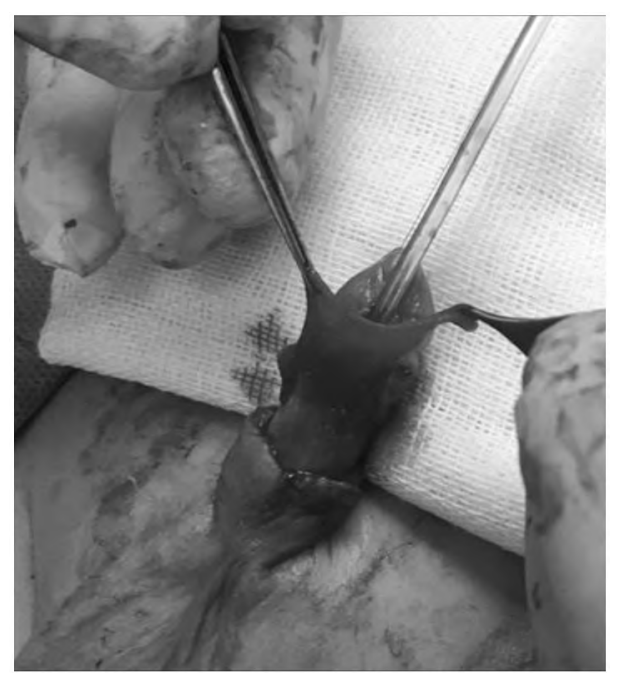

Fig. (5): Ventral dartos flap during redo TIP urethroplasty.

Regarding the surgical technique used for redo hypospadias surgery, our results showed that the highest success rate $(70 \%)$ was reached in the group of patients who underwent two stage repair with buccal mucosa graft while is decreased to $(58.33 \%)$ in the group of patients who underwent TIP urethroplasty. The lowest success rate (50\%) was observed in the group of patients who underwent Mathieu urethroplasty and transverse dorsal preputial onlay flap urethroplasty with no statistically significant difference between the four techniques.

\section{Discussion}

Redo hypospadias surgery is a challenging procedure as the results of this surgery and its success rate are usually less than that of the primary cases. Meanwhile, the parents are usually looking for better results in the redo surgery. In this project, we included 42 patients with failed hypospadias repair who were scheduled for redo surgery. We have excluded cases with simple fistula closure to include only cases that were in need for urethroplasty. We used four techniques for this surgery that included TIP, Mathieu, transverse dorsal preputial onlay flap and two-stage repair with buccal mucosal graft. The technique was selected according to the surgical needs of each individual case.

Our late complications included; 8 cases $(19.04 \%)$ with recurrent hypospadias due to complete wound disruption or glanular dehiscence, 6 cases with urethrocutaneous fistula (14.28\%) 5 cases with meatal stenosis (11.90\%) and 2 cases with anterior urethral diverticulum $(4.76 \%)$. This was in agreement with that reported by Catti et al., [6] who described the incidence of fistula in redo hypospadias repair was as high as $20 \%$ and this was more common with free graft use like buccal mucosal graft than grafts with a pedicle. Bracka [7]reported his experience with 600 patients with primary and secondary hypospadias repairs; he concluded that the second layer largely decrease the incidence of fistula from $63 \%$ without a second layer to only $5.4 \%$ with the use of dartos flap as a second covering layer. Yang et al., [8] demonstrated that meatal stenosis is the most common complication in reoperative TIP urethroplasty especially in distal types. Although a wide neomeatus was made, meatal stenosis was the most common complication. The results were also similar to Snodgrass and Lorenzo [9] who reported meatal stenosis after the usage of TIP urethroplasty to repair proximal hypospadias. Although their cases were proximal, complications in reoperation were 3 in $15(20 \%)$, and were similar to those reported by Shanberg et al., [10] and Borer et al., [11] (24\%, 15\% respectively).

We have stratified our final results into three categories which included successful repair, failed repair and minor complications. This classification was based on the fact that the minor complication can be easily dealt with whereas the failed repair will be a difficult task later one.

The overall success rate of our patients showed that 24 of the 42 patients $(57.14 \%)$ included in this study had successful repair while 8 patients $(19.04 \%)$ had failed repair with recurrent hypospadias due to complete wound disruption or glanular dehiscence and needed another redo surgery and minor complications were reported in 10 cases $(23.80 \%)$. This was in arrangement with Snodgrass et al., who reported that 135 of 1085 patients (12\%) had failed redo hypospadias repair due to glanular 
dehiscence, urethrocutaneous fistula, meatal stenosis and urethral stricture [12].

We have also studied the different factors that could affect the success rate of our patients and our statistical analysis showed that the number of previous operations and the final localization of the hypospadiac urethral meatus after penile orthoplasty were the only significant factors in this regard. Snodgrass et al., used logistic regression in 1536 patients to demonstrate that each prior surgery increased the odds ratio of subsequent urethroplasty complications by 1.5 folds [12]

Snodgrass et al., showed that, small glans width was a risk factor for urethroplasty complications in patients undergoing redo surgery with $16 \%$ complications with small glans width $<14 \mathrm{~mm}$ and $12 \%$ when it was $>14 \mathrm{~mm}[13]$

In our study, there were 12 patients who underwent TIP repair and we demonstrated a failure rate $41.66 \%$. Two patient developed complete wound disruption, two patients with urethrocutaneous fistula and one patient with meatal stenosis.

Elicevik et al., reported that TIP urethroplasty is a safe and efficacious alternative procedure for hypospadias reoperations if the urethral plate has no scars and outcome is favorable if the first failed repair was a meatal based flap procedure. In their series of 100 patients who had undergone a redo TIP urethroplasty, the overall complication rate was $26 \% .18$ patients $(18 \%)$ had fistula, 5 patients $(5 \%)$ had meatal stenosis, two had dehiscence $(2 \%)$ and one had neourethral stenosis (1\%) [14].

In our study, there were 10 patients who underwent redo Mathieu urethroplasty and we demonstrated a failure rate of $50 \%$. Two patients developed complete wound disruption, one patient developed glanular dehiscence, and two patients were complicated by urethrocutaneous fistula associated with meatal stenosis.

Rabinowitz reported his series of 59 Mathieu urethroplasty, 8 of which were salvage procedures with a 75\% success rate [15]. Secrest et al., reported that redo Mathieu urethroplasty had been performed in 34 of 65 patients who required urethral reconstruction. The procedure was definitive in 18 patients $(53 \%)$, but the other 16 patients required additional surgery. Simple local procedures were performed in 3 of these patients for repair of meatal stenosis and small fistula; the other 13 patients underwent various urethral reconstructive procedures [16]
In our study, there were 10 patients who underwent transverse preputial onlay flap for redo hypospadias repair and we demonstrated a failure rate of $50 \%$. One patient developed complete wound disruption; one patient was complicated by urethrocutaneous fistula, one patient with meatal stenosis and two patients with anterior urethral diverticulum.

The outcome of transverse preputial island flap technique varies greatly in the literature due to differences in meatal location, chordee and phallic size [17]. Elder et al., reported a complication rate of $6 \%$ among 50 patients with distal and middle hypospadias who needed redo surgery [17]. For middle and posterior hypospadias, Hollowell et al., [18], Mollard et al., [19], Baskin et al., [20], Powell et al., [21] and Demirbilek et al., reported $10 \%, 9 \%, 8.6 \%, 25 \%$ and $16 \%$ complication rates respectively [22].

We reported in our study 10 patients with recurrent hypospadias who needed redo operation with two stage repair using buccal mucosal graft. We demonstrated a failure rate of $30 \%$. One patient with complete wound disruption, one patient with glanular dehiscence and one patient developed urethrocutaneous fistula associated with meatal stenosis.

Barroso et al., used two stage buccal mucosa graft in 10 children in whom previous hypospadias repair had failed. Complication rate was $20 \%$ (2 cases) one developed fistula and one wound infection [23] . Snodgrass and Elmore performed two stage buccal mucosa graft in 25 patients who underwent reoperation for hypospadias. Graft contracture or significant focal scarring was evident in $12 \%$ of cases, all were patched before tubularization [24]

Lastly, we have to notice that some of our cases were in need for another operation after what we have done, but some of these subsequent surgeries were simple as meatotomy or simple fistula closure. On the other hand some cases had more difficult complications such as complete wound disruption. However, because of the small number of patients in this project we were not able to put the two categories of complications in two separate entities in our statistical analysis. Therefore, we put all of them together in one package.

As a matter of fact, no single operation can be applied to all cases of hypospadias. Therefore, we have tried to select the best operation for each individual case and consequently, the study can't be designed as a randomized trial. However, this 
added some difficulties in our assessment of our results because all cases were not the same.

\section{Conclusion:}

TIP urethroplasty is an effective technique for redo hypospadias repair if the patient has a good and wide urethral plate. Similar results can also be achieved by Mathieu's repair or transverse onlay flap in patients with narrow and non-scarred urethral plate. However, patient with scarred unhealthy urethral plate should have a two-stage repair with buccal mucosa graft.

\section{References}

1- CANON S., MOSLEY B., CHIPOLLINI J., PURIFOY J.A. and HOBBS C.: Epidemiological assessment of hypospadias by degree of severity, J. Urol., 188: 236165, 2012.

2- CASTAGNETTI M. and EL-GHONEIMI A.: Surgical management of primary severe hypospadias in children: Systematic 20-year review. J. Urol., 184: 1469-74, 2010.

3- RYNJA S.P., De JONG T.P., BOSCH J.L. and De KORT L.M.: Functional, cosmetic and psychosexual results in adult men who underwent hypospadias correction in childhood. J. Ped. Urol., 7: 504-15, 2011.

4- CIMADOR M., VALLASCIANI S., MANZONI G., RIGAMONTI W., De GRAZIA E. and CASTAGNETTI M.: Failed hypospadias in pediatric patients. Nat. Rev. Urol., 10: 657-66, 2013.

5- AL-SAYYAD A., G. PIKE J. and LEONARD M.P.: Redo hypospadias repair: Experience at a tertiary care children's hospital, C.U.A.J., 1 (1): 47-51, 2007.

6- CATTI M., DEMEDE D., VALMALLE A.F., MURE P.Y., HAMEURG F. and MOURIQUAND P. Management of severe hypospadias. Indian J. Urol., 233-9, 2008.

7- BRACKA A.: Hypospadias repair; the two stage alternative, Br. J. Urol., 76: 31-41, 1995.

8- YANG S.S., CHEN S.C., HSIEH C.H. and CHEN Y.T.: Reoperative Snodgrass procedure. J. Urol., 166: 2342-5, 2001.

9- SNODGRASS W.T. and LORENZO A.: Tubularized incised-plate urethroplasty for hypospadias reoperation. B.J.U. Int., 89: 98-100, 2002.

10- SHANBERG A.M., SANDERSON K. and DUEL B: Reoperative hypospadias repair using the Snodgrass incised plate urethroplasty, B.J.U. Int., 87: 544-7, 2001.
11- BORER J.G., BAUER S.B., PETERS C.A., et al.: Tubularized incised plate urethroplasty: Expanded use in primary and repeat surgery for hypospadias. J. Urol., 165: 581-5, 2001.

12- SNODGRASS W. and BUSH N.C.: Re-operative urethroplasty after failed hypospadias repair: How prior surgery impacts risk for additional complications, Journal of Paediatric Urology, 13, 289, 1-6, 2017.

13- SNODGRASS W., KOYLE M., MANZONI G., HURWITZ R., CALDAMONE A. and EHRLICH R.: Tubularized incised plate hypospadias repair for proximal hypospadias, J. Urol., 159: 2129-31, 1998.

14- ELICEVIK M., TIRELI G., DEMIRALI O., UNAL M. and SANDER S.: Tubularized incised plate urethroplasty for hypospadias reoperations in 100 patients. J. Int. Urol. Neph., 39: 823-27, 2007.

15- RABINOWITZ R.: Outpatient catheterless modified Mathieu hypospadias repair. J. Urol., 138: 1074-6, 1998.

16- SECREST C.L., JORDAN G.H., WINSLOW B.H., et al.: Repair of the complications of hypospadias surgery. J. Urol., 150: 1415-18, 1993.

17- ELDER J.S., DUCKETT J.W. and SNYDER H.M.: Onlay island flap in the repair of mid and distal penile hypospadias without chordee, J. Urol., 138 (2): 376-9, 1987.

18-HOLLOWELL J.G. KEATING M.A. and SNYDER H.M. Preservation of the urethral plate in hypospadias repair: Extended applications and further experience with the onlay island flap urethroplasty. J. Urol., 143: 98-102, 1990.

19- MOLLARD P., MOURIQUAND P. and FELFELA T.: Application of the onlay island flap urethroplasty to penile hypospadias with severe chordee. Br. J. Urol., 68: 317 9, 1991.

20- BASKIN L.S., DUCKETT J.W., UEOKA K., et al.: Changing concepts of hypospadias curvature lead to more onlay flap procedures, J. Urol., 151: 181-96;, 1994.

21- POWELL C.R., MCLAEER I., ALGARI M., et al.: Comparison of flaps versus grafts in proximal hypospadias surgery. J. Urol., 163: 1286-9, 2000.

22- DEMIBILEK S., KANMAZ T. and YUCESANS S.A.G.: Outcome of one stage technique for proximal hypospadias repair, J. Urol., 58: 267-70, 2001.

23- BARROSO U. and Jr. MACEDO A.: Initial experience with "inverted U" staged buccal mucosa graft (bracka) for hypospadias repair, J. Ped. Urol., 2008.

24- SNODGRASS W. and ELMORE J.: Initial experience with staged buccal mucosa graft (Bracka) hypospadias reoperations. J. Urol., 172: 1720-4, 2004. 


\section{إعادة تصليح مجرى البول فى حالات الإحليل السفلى المرتجعة}

آوضحت هذه الدراسة آن طريقة سنودرجراس هى آكثر الطرق نجاحاً فى إصلاح الإحليل السفلى المرتجعة عند إتساع الصفحة الإحليلية

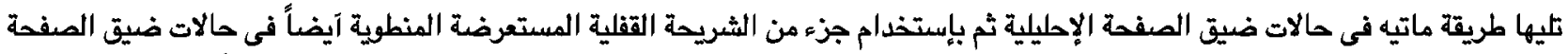

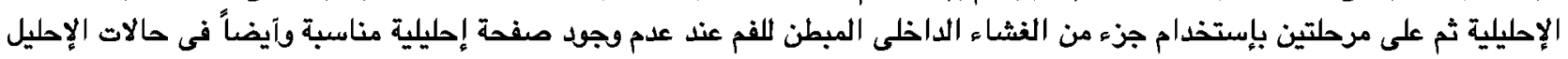

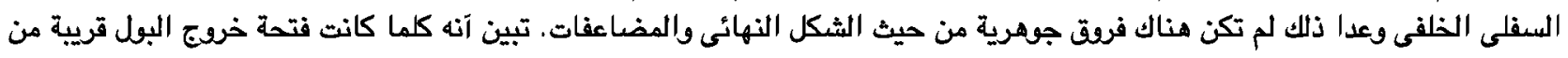
رآس القضيب كلما كانت زادت نسبة نجاح العملية والعكس صحيح. 